\title{
Experience and the Passage of Time*
}

\author{
Bradford Skow
}

\section{Introduction}

Some philosophers believe that the passage of time is a real phenomenon. And some of them find a reason to believe this when they attend to features of their conscious experience. In fact this "argument from experience" is supposed to be one of the main arguments for passage. What exactly does this argument look like? Is it any good?

There are in fact many different arguments from experience. I am not sure I understand them all. In this paper I want to talk about the three most interesting arguments that I do understand. ${ }^{1}$ I am going to argue that all three of them fail.

\footnotetext{
*Published in Philosophical Perspectives 25: Metaphysics (2011), pp.359-387.

${ }^{1}$ I will not say anything about A. N. Prior's “Thank Goodness That's Over" argument (Prior 1959) because it is not an argument from experience (even though it is often said to be). Here is Prior's argument: I can be glad that my ordeal is over without being glad that my ordeal is earlier than this thought or that my ordeal is earlier than 12 noon. But the latter two propositions are the propositions that some opponents of passage (the ones Prior knew) identified with the proposition that my ordeal is over. Prior concluded that the object of my propositional attitude is a proposition that only proponents of passage believe in.

Phenomenal experience does not play an important role in this argument. True, there is some distinctive phenomenal "feel" that (sometimes? usually? always?) occurs when I am glad about something. But what matters for Prior's argument is the propositional attitude component of gladness, not the phenomenological component. The argument is about the objects of that propositional attitude. (Callender (2008) mentions some other arguments advertised as connecting experience and passage that, like Prior's, do not in fact do so.)
} 


\section{The Passage Thesis}

We should begin at the beginning: what are the theories of time under dispute here?

In one corner we have the B-theory. The B-theory says: there are times; the times are structured by the relation $x$ is $r$ seconds earlier than $y$; this relation gives time the same order and metric structure as the real numbers. And that is all.

In the other corner we have the moving spotlight theory. The moving spotlight theory says that the B-theory leaves something out. In addition to the characteristics the B-theory says time has, there is also this: exactly one time has the intrinsic property presentness. (Maybe things located at that time and events that occur at that time also have presentness.) Presentness is the "spotlight" that shines on just one time. Moreover, which time has presentness changes. Some time has it, but later times will have it, and earlier times have had it. The spotlight moves along the series of times at a steady pace. It is this continual change in which time has presentness that in the moving spotlight theory constitutes the passage of time, or "objective becoming." When B-theorists deny that the passage of time is a real phenomenon they mean to deny that anything like this goes on; there is no such property as presentness that is instantiated first by earlier and then by later times. (There are, of course, other things "the passage of time" might mean and when it has one of those other meanings a B-theorist might accept the sentence "The passage of time is a real phenomenon.")

There are four comments I should make about these theories.

First, I have just presented one version of the B-theory. There are other versions. Some versions disagree with my version about the structure of time. They say that time has a metric structure but no intrinsic ordering. In those versions there is no intrinsic difference between the future and the past directions in time. Other versions of the B-theory say what my version says about the structure of time but then say something different about which relation "gives" time that structure. (In the version I presented a name for a unit of measurement ("second") appears in the predicate that expresses the relation that gives time its structure. Some might find this objectionable.) Still other, more radical versions say that time has an order but not a metric structure, or that time has a first, or a last, moment. And there are still 
other versions as well. The differences between these versions will not matter here.

Second, the moving spotlight theory is not the only theory that endorses passage. There are other "A-theories" of time, including presentism and the "growing block" theory. I focus on the moving spotlight theory in this paper because I think it is the best A-theory of time (though I will not defend this claim here). I am not sure how good the arguments I will discuss would look (or even how they would be formulated) if my target were instead, say, presentism. But for reasons of space I cannot give a separate discussion of the argument from experience for each Atheory.

Third, as I have formulated them the B-theory and the moving spotlight theory are both versions of substantivalism: they say that there are such things as times. Some philosophers reject this view. They say that while there are events and temporal relations between events (they agree that World War II occurred after World War I) there are no times at which those events are temporally located. This debate, again, will not matter in what follows.

Fourth, my statement of the moving spotlight theory is likely to mislead if it is not accompanied by some comments on the language in which the theory is formulated. That language contains tense operators, including the operators "It will be the case that..." and "It was the case that..." When the moving spotlight theorist says "A time later than $\mathrm{T}$ will have presentness" he is abbreviating a sentence that contains one of these operators - namely, "It will be the case that a time later than T has presentness." These tense operators are "primitive." Truth-conditions for sentences containing them cannot be given using quantification over times. So the moving spotlight theorist says that the following is false:

(1) "It will be the case that $\mathrm{T}$ has presentness" is true at $\mathrm{T}^{*}$ iff at a time later than $\mathrm{T}^{*}, \mathrm{~T}$ has presentness.

Why does the theory need primitive tense operators? Two connected reasons. First, the moving spotlight theorist insists that "It will be the case that $\mathrm{T}$ has presentness" is true simpliciter. But (1) says that its truth is relativized to times. Second, the truth-conditions in (1) treat presentness as a relation between times. But, the 
moving spotlight theorist says, it is not; it is an intrinsic property..$^{2}$

\section{The Argument from the Content of Experience}

Some B-theorists have thought they could defuse all arguments from experience without having to figure out just how those arguments work. They argue: supposing that the moving spotlight theory is true, my experience would be just the same if the B-theory were true, and vice versa. So experience cannot favor the moving spotlight theory over the B-theory $!^{3}$

This is a bad argument. Even if it is true that each of the theories is consistent with my experience being as it is, it does not follow that the fact that my experience is that way fails to favor one of the theories over the other. This is an instance of a general epistemological truth: a body of evidence can support some hypothesis without entailing that hypothesis. A body of evidence, for example, may be consistent with each of two hypotheses but may be better explained by one hypothesis than it is by the other. In that case the evidence favors the hypothesis that better explains it. As we will see, some ways of putting together an argument from experience say that the moving spotlight theory better explains some feature of our experience. Let us get on to what those arguments look like.

Here is a line of thought that leads to one of them. B-theorists admit that

${ }^{2}$ This is a compressed version of the argument that the moving spotlight theory needs primitive tense operators. The argument may not be sound; there may be versions of the moving spotlight theory that do without primitive tense operators. But for the purposes of this paper we do not need to worry about whether this is so. (See Zimmerman (2005) for a discussion of how best to formulate the moving spotlight theory of time. Several different versions of the theory are described in (Skow forthcoming).)

Moving spotlight theorists need not say that every tensed sentence abbreviates a sentence containing primitive tense operators. They might sometimes mean by tensed sentences just what B-theorists mean. So it might be that when a moving spotlight theorist says "Greta won the race" what he says is true iff there is a time $\mathrm{T}$ earlier than the time of utterance such that Greta wins the race at $\mathrm{T}$.

${ }^{3}$ Price (1996, 14-15) gives this argument and Prosser (forthcoming-a) endorses it. Maudlin (2007) denies the premise. But the argument is bad even if the premise is granted. 
there seems to be an objective passage of time. They just say that this is an illusion. Moving spotlight theorists, on the other hand, say that things are as they seem. Time really does pass.

A moving spotlight theorist might stop here and argue: his theory is superior because it is only in his theory that things are as they seem $4^{4}$ But this is not a good argument. A B-theorist might have an excellent story to tell about why things are not as they seem. If he does then it should not count against his theory that it says we are subject to an illusion.

So a better way to run the argument is to look at what each theory says about why time seems to pass. The argument will be that the moving spotlight theory's explanation is better than the B-theorists' explanations, and so (other things being equal) we should believe the moving spotlight theory.

To understand this argument we must know what "time seems to pass" means as it occurs in the argument. Now there are lots of things that "time seems to pass" can mean. Here is one thing someone might say about it:

When I say that time seems to pass I have in mind the following kind of thing. This weekend is my tenth college reunion. So I have been thinking about my college years all day. I haven't thought about that stuff since the last reunion, five years ago. It all seems so much further in the past now! That is the kind of thing I am talking about when I say that time seems to pass.

This cannot explain what "time seems to pass" means in the argument I am discussing. That is because in the argument I am discussing the B-theorist follows up his admission that time seems to pass with "but this is just an illusion." But any B-theorist who meant what the (fictional) speaker means by "time seems to pass" would not say this. For (if the B-theory is true) there is nothing that the speaker is wrong about. His college years seem farther in the past; and they are farther in the past. The temporal distance between his act of thinking and the time he was in college is greater.

\footnotetext{
${ }^{4}$ This seems to be the argument in (Hare 2010).
} 
So if there is an argument here for the moving spotlight theory then "time seems to pass" as it occurs in the argument must mean something else. What else? Comparing the moving spotlight theory and the B-theory to realism and eliminativism about color suggests an interpretation 5 Realists and eliminativists about color agree that ripe tomatoes seem red. This seeming is, of course, a "visual" seeming: realists and eliminativists agree that ripe tomatoes look red. They agree that ripe tomatoes are visually represented as red. Or, to say the same thing in a more complicated way, they agree that the experience I have when I look at a red tomato has the propositional content that the tomato is red ${ }^{6}$ Realists about color go on to say that ripe tomatoes are, in fact, red. They are as they look; our experience represents them correctly. Eliminativists deny this. They say that while tomatoes look red this is just an illusion.

One straightforward interpretation of "time seems to pass" is that it, like "tomatoes look red," is a claim about the content of some experience or experiences. On this interpretation B-theorists and moving spotlight theorists agree that the content of (some of) our experiences includes the proposition that there is objective becoming. Their disagreement is about whether the world is as our experience represents it to be. What makes this interpretation plausible is that B-theorists like to follow their concession that time seems to pass with "but this is just an illusion." An illusion is a kind of mis-representation. So if the passage of time is an illusion there must be a (mis)representation around that represents its occurrence.

A more precise statement of the argument from the content of experience, then, is this: $: 7$ experience favors the moving spotlight theory over the B-theory be-

\footnotetext{
${ }^{5}$ Several philosophers make this comparison; it goes back at least to (Grünbaum 1967).

${ }^{6}$ Some philosophers deny that "the tomato looks red to me," "the tomato is visually represented as red to me," and "I am having a visual experience with the content that the tomato is red" are all equivalent. But - with one exception, which I will come to shortly - there is no harm in this context in treating them as equivalent. (See (Byrne 2009a) for discussion.)

${ }^{7}$ There is another argument that I might have called "the argument from the content of experience." That argument goes: the moving spotlight theory better explains why and how our experiences represent things as changing than the B-theory does. (Among others, Le Poidevin (2007) and Dainton (2011) discuss something
} 
cause the moving spotlight theory has a better explanation of the fact that (some) experiences have the content that time passes..$^{8}$

To begin evaluating this argument let us look at the assumption it starts with: the assumption that our experiences (some of them at least) have the content that time passes. Now the objective passage of time consists in change in which time has presentness. 9 So if some of our experiences have the content that time passes, then some of our experiences have the content that some time has, or some things that exist in time have, presentness. ${ }^{10}$ And if some experience has the content that something has presentness, then, it seems safe to assume, some visual experience does. So the assumption the argument starts with entails that some things are visually represented as having presentness. Some things look like they have presentness. Which things? Presumably all the things I see. This apple, that chair, the blackboard - each does not just look to have a certain shape and a certain color. Each one also looks like it has presentness.

Is this true? I am not sure. It would help if I had some conception of what something has to look like in order for it to look like it has presentness. A ripe tomato and a firetruck look very different in many respects, but there is also a

like this argument.)

I will not say anything about this argument in the body of this paper. Here are some brief comments on it. The argument might appeal to the idea, common among A-theorists, that there is no "real change" in the B-theory (this idea goes back at least to McTaggart (1908)). If this premise were true the argument might have something going for it; but the premise is false (I have nothing to add to what other B-theorists have said about why it is false). If the argument does not appeal to this premise then I do not think the argument is even initially appealing.

${ }^{8}$ Remarks that suggest this argument may be found in many places. Some places where it is relatively explicit are: (Smart 1980, 10), (Hestevold 1990, 541), (Taylor 1992, 81), (Smith 1994, 357), and (Paul 2010, 334-39). But there may be alternative interpretations of each of these texts.

${ }^{9}$ According to the moving spotlight theory, at least. But that is the only theory of passage I am considering in this paper.

${ }^{10}$ I write "has presentness" rather than "is present" to emphasize that the experience (allegedly) represents the intrinsic property that moving spotlight theorists believe in and B-theorists do not. Later in the paper I will revert back to the more natural "is present." 
salient respect in which they look similar. And there is a respect in which both look different from oranges and chocolate bars. It is (at least in part) by attending to these similarities and differences that I get a grip on what something has to look like in order for it to look red. But the analogous procedure for getting a grip on what something has to look like in order for it to look like it has presentness does not work. For either everything or nothing I see looks like it has presentness ${ }^{11}$

I will have to press on without this kind of conceptual help. Now "the tomato looks like it has presentness" strikes me as false. Actually, my response is much stronger: it strikes me as crazy, as absurd. But I do not want to place much weight on this judgment. For it may strike me as false only because I use the word "looks." Compare: does the tomato look like it exists? I find this question baffling. Nevertheless, I do think that my visual experience has the content that the tomato exists. (Or at least I find this harder to deny.) Maybe, similarly, my visual experience represents that the tomato has presentness even though it sounds wrong to say that the tomato looks like it has presentness.

So far I have reached no conclusion about whether things look like they have presentness. Here is one argument someone might give in favor of this claim. We agree that my visual experience represents that there is a tomato. But "is" here is the present tense form of the verb "to be." And representing that something is (present tense) $\mathrm{F}$ is sufficient for representing that it has presentness.

I do not think that this is a very good argument in this context. A moving spotlight theorist might accept this sufficient condition for representing that something has presentness. But no B-theorist will. And what we want right now is a reason to think that things are represented as present that even B-theorists can recognize.

This is as far as I have got in my thinking about the claim that everything I see is visually represented as having presentness. I have not found a decisive reason to accept this claim, but I also have not found a decisive reason to reject it. In order to

${ }^{11}$ I suppose someone could say that in normal conditions everything I see looks like it has presentness, but there are very rare and very strange circumstances in which I can see something that does not look like it has presentness. But I do not know of anyone who has said this or said what those circumstances are, so this possibility is no help in the present context. 
make some progress I am going to grant that it is true. The argument from content is in trouble even if this claim is granted.

I should say one more thing about the status of this claim. I arrived at it from the assumption that some experience represents that something has presentness. But moving spotlight theorists do not need to agree that some visual experience has this content. Of course, the moving spotlight theorist is hardly better off saying that it is only auditory experiences that represent time passing. How odd it would be to say that things sound like they have presentness but nothing looks like it has presentness. But they could maintain that no experience that comes to us from the five senses represents that something has presentness. Only experiences that come from introspection have this content. So, the thought is, it does not look like time passes, or sound like time passes. Apples do not look present and trains do not sound present. Instead we have experiences as of the passage of time only when we look "inward." It is our own internal states, the states that are the objects of introspection, that appear present. Some moving spotlight theorists might think that this is a more plausible claim than the claim that things look present.

Introspection is a difficult topic. Some philosophers deny that we have a quasi-perceptual faculty of introspection, an "inner eye" with which we may gaze on our own internal states. (Byrne (forthcoming), building on some remarks by Evans $(1982,226)$, defends this view.) If our inner states do not appear to us any which way at all then they do not appear present and the move to introspection has not helped. But suppose Byrne is wrong and we do have introspectable experiences. Then I am also willing to grant for the sake of argument that when I introspect an experience it is represented as present. However, in what follows I will stick to the case of visual experience. I do not think anything turns on making this choice.

So let us assume that time does seem to pass. Which theory of time better explains why this is so? It can look like the B-theory is at an initial disadvantage here. The idea is that if time does pass then it is relatively easy to explain why it seems to pass. The moving spotlight theorist just needs to say that this is an instance of veridical perception. So, the thought goes, the moving spotlight theory already has a relatively good explanation of the fact that time seems to pass. To defend the B-theory B-theorists must produce a better explanation. And what they have to 
explain is why our experiences represent a property (or represent things having a property) that nothing can have. And that has got to be relatively hard to do. What will the B-theorist say is the cause of this illusion?

B-theorists have proposed explanations, some more detailed than others. (See, for example, (Smart 1980), (Paul 2010), and (Prosser forthcoming-b).) But (continuing to grant that there is something to be explained here) I do not think we need to know the details of the B-theorists' explanations to know that the argument from the content of experience is no good. That is because the moving spotlight theory's explanation, as it currently stands, is terrible.

Moving spotlight theorists want to explain why thinks look like they have presentness by appealing to the fact that those things in fact have presentness. So they think that presentness is a visible property, a property we can veridically perceive something to have by looking at it. They think that presentness is, in this respect, like redness and squareness but unlike (say) electrical charge. Square things look square in part because they are square, but nothing looks negatively charged.

For their explanation of the fact that time seems to pass to be any good moving spotlight theorists need to offer us some story explaining how (if their view is correct) presentness manages to be visible rather than invisible. Otherwise their explanation of the fact that time seems to pass has a big hole in the middle. But I have never seen a moving spotlight theorist, or any A-theorist, tell such a story.

I have doubts about whether such a story can be told. ${ }^{12}$ My doubts emerges from thinking about an argument for a different conclusion. D. H. Mellor argued that "we do not observe the tense of events," and some (including Hestevold (1990, 541)) have read Mellor's argument as an argument that nothing looks present 13 The argument does not establish this conclusion; that is why I did not give it above. But it leads us to where we now want to go. Here is the argument: I look through a telescope and see a star. Unbeknownst to me the star is no more. It died in a supernova years ago. But the star was so far away when it died that the light from

\footnotetext{
${ }^{12}$ Prosser $(2007,88)$ gives an argument for this claim that in some respects resembles the one to follow. (See also (Prosser forthcoming-a).)

${ }^{13}$ Mellor's argument is on page 26 of Real Time (1981). I have modified the example in the argument.
} 
the supernova has not yet reached the earth. Later I go to the planetarium for a lecture on that star. The planetarium is so good that when I look at the ceiling things looks exactly as they did when I looked through the telescope. Hestevold concludes: "since past events [or past things] appear through the telescope to an observer in the same way that present events [or things] appear to the observer," nothing looks like it has presentness.

The problem with this argument is obvious: from the fact that the star and the ceiling look the same it does not follow that neither looks present. Maybe they both look present. It does not matter that the star is no longer around and does not have presentness. If this is not obvious enough on its face consider the analogy with redness. Suppose I turn my telescope onto another star, one that still exists. That star looks red. In fact its color is indistinguishable from that of the tomato on my desk ${ }^{14}$ Unbeknownst to me the star is no longer red. Its color has changed as it has aged. But the star is so far away that the light indicating its current color has not yet reached the earth. It would be wrong to conclude: since non-red things appear through the telescope to an observer in the same way as red things, nothing looks red.

The second star looks red to me, even though it is not red, in part because it was red when the light reaching me departed the star. The moving spotlight theorist might say something similar about the first star: the first star looks like it has presentness, even though it does not, in part because it had presentness when the light reaching me departed the star.

But the analogy between redness and presentness here falls apart when you think about it more. The picture in figure 1 captures what is going on when the star looks red even though it no longer is. (In this and all other figures, the stick figure depicts me.) The star is 500 light years away. Back in 1511 the star was red and red light left the star. That light hits my eyes in 2011. The star looks red to me.

What picture captures what is going on when the star looks present even though it no longer is? Maybe the picture in figure 22? In that picture the yellow halo indicates which time (and which things) have presentness.

\footnotetext{
${ }^{14}$ I do not spend much time looking at the stars. Perhaps no star could look the same in color as any tomato. If you think so then substitute a different example.
} 
Figure 1: The Brown Star Looks Red

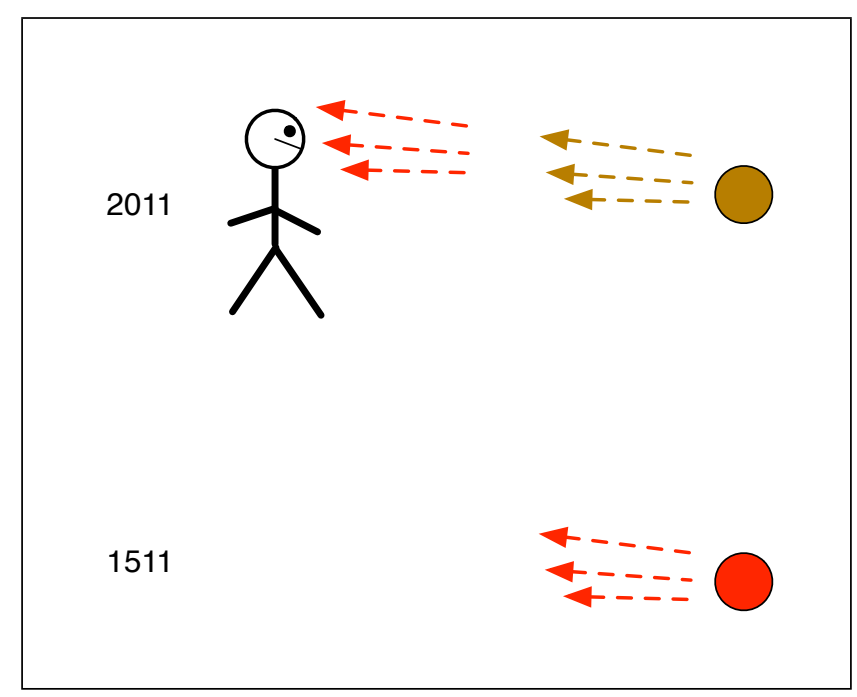

Figure 2: The Star Looks Present?

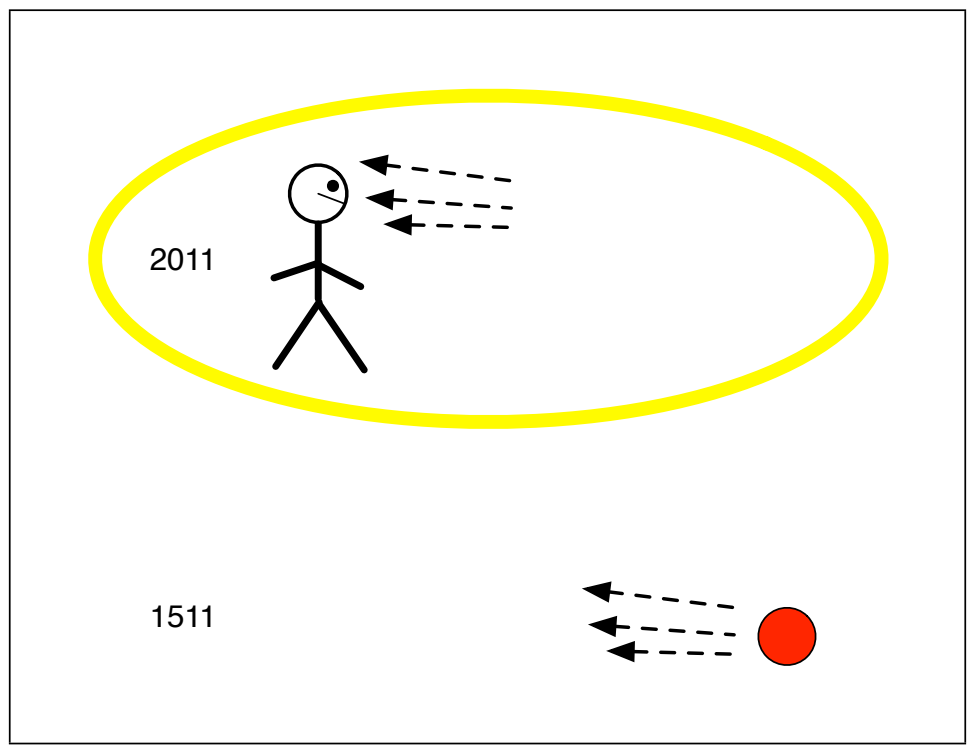

This picture cannot be the right picture. For in it the light leaves the star in 1511, but the star does not have presentness. The story we are told, though, is that 
the star had presentness when the light left it.

We are running up against the feature of the moving spotlight theory that makes the theory so hard to grasp. In that theory things and times have, or lack, presentness simpliciter. They do not have, or lack, presentness at some times and not at others. So while the light leaves the star in 1511, the star does not have presentness in 1511. It also does not lack presentness in 1511. It lacks presentness simpliciter.

Of course, the moving spotlight theorist will say, it was the case that the star has presentness. But it is false that "it was the case that P" is true iff there is some earlier time at which $\mathrm{P}{ }^{15}$ So the moving spotlight theorist may reply that we need to consider the picture in figure 3 along with the picture in figure 2 . In the picture in figure 3 the star does have presentness. The picture in figure 2 depicts what is the case; the picture in figure 3 depicts what was the case.

Figure 3: It was the case that...

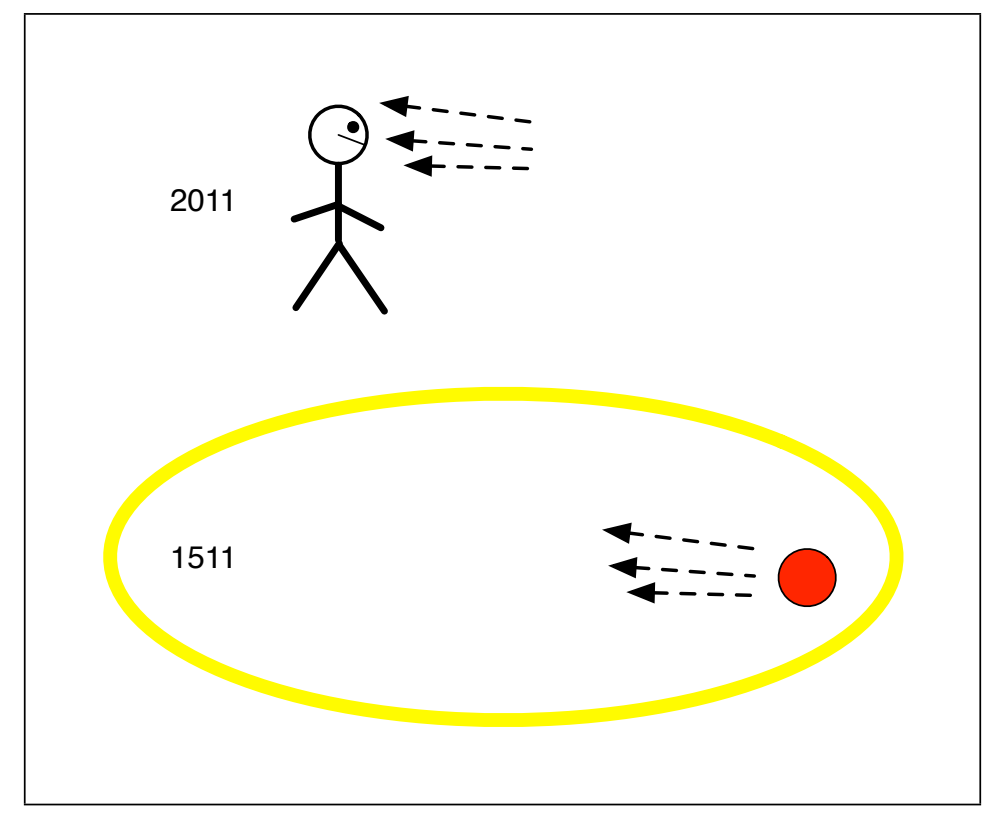

\footnotetext{
${ }^{15}$ Instances of this schema are true for many sentences P; but not for all of them. This will come up again below.
} 
But this only makes things worse. In one picture the star has presentness and in the other it does not. But the exact state of the photons leaving the star is the same in both pictures. Photons of the same frequencies depart in the same directions. And the exact state of the photons arriving at my retina is the same in both pictures. It is hard to see how presentness can be a visible property if this is true.

Think about why redness is visible. Redness is a visible property because things that have redness interact with light differently from things that lack it. (This is not to say that no non-red thing ever looks red, just that this requires special circumstances.) That kind of story about why presentness is visible has been ruled out. We have just seen that having presentness makes no difference to the way something interacts with light.

Of course, in my argument that presentness makes no difference I assumed that when the spotlight moves from one time to another nothing else changes. Figures 2 and 3 differ only over the location of the halo. (More carefully, I have assumed that if $\mathrm{S}$ is a sentence that does not contain "presentness" (or any other name for or description of that property) and does not contain any primitive tense operators then "It was the case that $S$ " is true iff $S$ is true.) Might a moving spotlight theorist abandon this assumption? He would have to say something like this: the haloed photons differ in some physical way (maybe they have different frequencies) from the unhaloed photons. It is false that the photons in 1511 are in the same physical state in both pictures. If the moving spotlight theorist says this then presentness does seem to be making a difference to the light leaving objects that have it.

But it is hard to take this suggestion seriously. It seems flat-out inconsistent with what we know about physics. In no physical theory that one might consult to figure out how light leaves that star does presentness play a role in determining the photons' state.

So if presentness is visible it cannot be visible for the same kinds of reasons that redness is visible.

This does not prove that presentness is not visible. For there may be other ways a property can be visible. Suppose I have a twin brother. And suppose that you do not know this and have never seen him. But you know me and see me all the 
time. One day my brother walks by your window and you see him for the first time. You certainly believe that I am walking by. And your visual experience certainly has the content that someone with qualitative features $\mathrm{F}$ is walking by (where $\mathrm{F}$ are the qualitative features I have). But maybe more is true: maybe your extended acquaintance with me also makes it the case that your visual experience has the content that Skow is walking by. Perhaps the property of being Skow is represented in your experience. If so then this property is visible even though my brother and I reflect light in just the same ways ${ }^{16}$

Maybe a story like this could be told about how presentness gets to be visible. I do not know how it would go. I would certainly like to see it. But in the absence of such a story the moving spotlight theorist does not have a better explanation for the fact that time seems to pass than the B-theorist. The argument from content does not succeed.

\section{The Argument from the Phenomenal Character of Experience}

I cheated a little bit when I reported Hestevold's conclusion about the star. He did not write "nothing looks like it has presentness." What he actually wrote is "being present is not a phenomenal property." Now "phenomenal property" has several uses in philosophy ${ }^{17}$ I am not sure which way Hestevold is using it. It may be that by "phenomenal property" he just means a property that may be represented by experience. Then although he used different words his conclusion is the conclusion I reported: nothing looks present. But he might mean something else by "phenomenal property." That something else suggests a different argument from experience.

Experiences do not just have representational content. They also have "phenomenal character." There is "something it is like" to have them. On one way of using "phenomenal property" talk about the phenomenal properties of an experience is talk about that experience's phenomenal character. When someone asks whether presentness is a phenomenal property, then, he may be asking whether experiences

\footnotetext{
${ }^{16}$ Siegel (2011) thinks that visual experience can have contents like this.

${ }^{17}$ Byrne (2009b) explores the confusions around its use.
} 
that have presentness "feel" different from experiences that do not.

Is there an argument in favor of the moving spotlight theory lurking around here? If there is it might go like this. The moving spotlight theorist starts by saying that, in his view, experiences that have presentness do indeed feel different from experiences that do not. He then says that this allows his theory to explain things that the B-theory cannot explain, or cannot explain well. This explanatory advantage, he continues, counts in favor of his theory. This, in outline, is the argument from the phenomenal character of experience (for short: the argument from phenomenology).

Like the argument from the content of experience, the argument from phenomenology attempts to show that the moving spotlight theory is explanatorily superior to the B-theory, and that for that reason we should believe it. The argument from phenomenology might seem good even in light of what I have said about the argument from content. Maybe the lesson of my discussion of the argument from content is that when arguing in favor of passage the best way to interpret "It seems like time passes" is not as a claim about the content of experience but instead as a claim about its phenomenal character.

I want to make another comment about the relationship between the argument from content and the argument from phenomenology. Many philosophers accept intentionalism: the thesis that the phenomenal character of an experience is determined by, or at least supervenes on, its representational content. If intentionalism is true then any moving spotlight theorist who says that experiences with presentness have a distinctive phenomenal character must also say that they have a distinctive representational content. Does this mean that if intentionalism is true then the arguments from content and from phenomenology are the same argument?

Not necessarily. A moving spotlight theorist might say that although experiences that have presentness differ in content from experiences that lack it, they do not differ over whether they represent anything as having presentness. Their content differs in some other way. (What other way? I have no idea. I am not suggesting that this is a plausible claim.) A moving spotlight theorist who says this rejects a premise of the argument from content. But he might still think that the argument from phenomenology was good. So that argument would still deserve independent 
consideration 18

Let us take a closer look at the argument. I have only presented an outline of the argument from phenomenology. I have not said what it is that the moving spotlight theorist aims to explain. That is because I do not know any way of filling in this detail that makes the argument plausible.

So what phenomenon is being explained? One candidate is: the fact that my current experiences feel like this. Now this is not a particularly informative characterization of the phenomenal character of my current experiences. But it will do for now.

My current experiences occur on Tuesday. So my current experiences are my Tuesday experiences. Those experiences have a certain phenomenal feel. The question is: why do those experiences feel that way? The moving spotlight theorist says: because they have presentness. The B-theorist will have some other explanation (it will not matter what it looks like).

Now as I phrased the question it looks like the moving spotlight theorist aims

${ }^{18}$ Many B-theorists talk about the phenomenal character of experience when they talk about the fact that time seems to pass. This suggests the argument from phenomenology. Then in the next breath they say that although it seems like time passes this is just an illusion. This suggests the argument from content. Maybe they talk like this because they think the arguments are the same. Anyway, for this reason it is hard to give examples of philosophers who definitely have the argument from phenomenology rather than the argument from content in mind. One philosopher who does at least sometimes seem to aim just at the argument from phenomenology is Prosser in his paper "Could We Experience the Passage of Time?" He writes that the objective passage of time is not "directly perceived through the outer senses in the same way as colors." That looks like a rejection of a premise in the argument from content. Then he goes on to say that "time seeming to pass is a feature of conscious experience with a distinctive phenomenology" (2007, 76-77). That looks like an endorsement of the premise in the argument from phenomenology. (I think that in the first part of this quotation Prosser means to make the stronger claim that visual and auditory experience do not represent objective passage, not the weaker claim that either they do not represent this or they do but what they represent is false. I should say that this interpretation does not perfectly fit everything Prosser says: some of the arguments in Prosser's paper, like the one I referred to in footnote 12 , are aimed at the argument from content.) 
to explain every aspect of the way my Tuesday experiences feel. But he need not be that ambitious. It would do if he had a good explanation for just some aspect of the way those experiences feel.

Okay, so, is the moving spotlight theory's explanation a better explanation of the feel of my Tuesday experiences? I am not going to answer this question directly. Instead I am going to discuss a related question: is the moving spotlight theory's explanation any good? If it is not then we can safely assume it is not better than the B-theorist's.

If the moving spotlight theory's explanation is to be any good then the moving spotlight theorist has to say that experiences that lack presentness, but are otherwise as similar as possible to my Tuesday experiences, have a different phenomenal character. Is that right? To answer it will help to reflect on an example. So suppose that I spent today (Tuesday) in a red room (everything in it is red); and I did so on Monday as well. On both days I have experiences as of red things, the same things on both days. Only the Tuesday experiences have presentness. ${ }^{19}$ but the experiences are otherwise the same. Then the moving spotlight theory says that things are as in figure 4

Do the Monday experiences feel different from the Tuesday experiences? I do not think so. I think that the Monday experiences have the same phenomenal character as the Tuesday experiences.

Suppose that I have a black-belt in autophenomenology. I can completely and accurately describe the phenomenal character of my experiences. These descriptions are so complete that no one description correctly describes experiences that are phenomenally different. And my ability to appreciate the phenomenal character of my experiences is so good that I always produce an accurate description of the phenomenal character of the experience I am describing. Now suppose that on Monday I produce such a description, and I do so again on Tuesday. I write these descriptions down on paper. I think it is obvious that the descriptions will be word-for-word the same.

If I am right that the Monday and Tuesday experiences have the same phe-

\footnotetext{
${ }^{19}$ I am speaking loosely. Only the experiences during one instant on Tuesday have presentness.
} 
Figure 4: The red rooms according to the moving spotlight theory

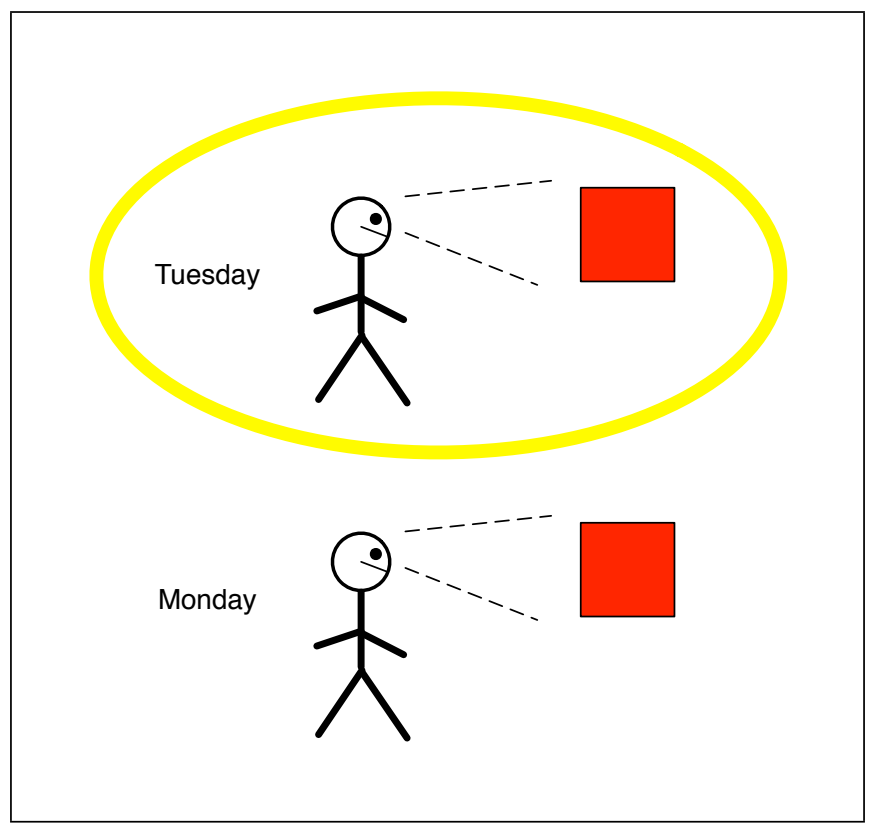

nomenal character then the fact that the Tuesday experiences have presentness cannot explain why they feel like this. So the moving spotlight theory does not explain why the Tuesday experiences have the phenomenal character they have.

I know how moving spotlight theorists will reply to all this. They will deny that the Monday and Tuesday experiences have the same phenomenal character. What it is like to have the Tuesday experiences differs from what it is like to have the Monday experiences. To have a name for this difference let us say that on their view only the Tuesday experiences feel "lustrous." Moving spotlight theorists will then say that the Tuesday experiences feel lustrous and the Monday experiences do not because only the Tuesday experiences have presentness 20 And, the reply concludes, B-theorists cannot explain why only the Tuesday experiences feel lustrous.

\footnotetext{
${ }^{20}$ By "E feels lustrous" some moving spotlight theorists might mean "E has some phenomenal character." These moving spotlight theorists think that if the B-theory is true then no experience has any phenomenal character. (Maybe they should not even be called "experiences.") This is Peter Forrest's view (Forrest 2004), except that Forrest defends the growing block theory, not the moving spotlight theory.
} 
There is more to this reply. Why am I inclined to think that the Monday and Tuesday experiences have the same phenomenal character? A moving spotlight theorist might say that I confuse this false claim with a true one. That is the claim that the phenomenal character the Tuesday experiences have is the same as the phenomenal character the Monday experiences had. That is, only the Tuesday experiences feel lustrous, but it was the case that only the Monday experiences feel lustrous. The phenomenal character of my experiences has changed. (This is a kind of change that only appears in the moving spotlight theory. For on the B-theory it cannot happen that my Monday experiences have a certain feel at one time (on Monday) and then a different feel at a later time (on Tuesday).)

What about the descriptions of the phenomenal character of my experiences that I wrote down? Since I have a black-belt in autophenomenology I know all about lustrousness. So I either wrote "lustrous" on both days or "lustrous" on neither day. ("Lustrous" is not the complete description; but it is the only part we are interested in now.) The moving spotlight theorist will probably say that I wrote "lustrous" on both days, even though only the Tuesday experiences feel lustrous. What then about the fact that I always produce accurate descriptions? He will say that understood one way this claim cannot possibly be true. For since the phenomenal character of a given experience changes, the accuracy of any description of it changes. No description of the phenomenal character of that experience can always be accurate. But there is another way to understand the claim so that it is true. Read it as the claim that I always produce descriptions that are accurate "when I produce them." That is, the description I write on Tuesday is accurate and the description I write on Monday was accurate. (But the description I write on Monday is inaccurate and the description I write on Tuesday was inaccurate.) That is as reliable as I can be about these things in the moving spotlight theory.

All I can say about this reply is that I continue to think that my Monday and Tuesday experiences have the same phenomenal character. (I wish I had more to say.) Nothing in the moving spotlight theorist's reply persuades me that I am confused when I think this. As a result, I do not think that there are any facts about the phenomenal character of my experiences that the moving spotlight theory is better placed to explain than the B-theorist. 
So I do not think that the argument from phenomenology is at all convincing. But I do think there is something interesting behind the argument. I just think that the argument from phenomenology is the wrong way to articulate that something. I think that when moving spotlight theorists are tempted to say that present experiences have a special feel it is because an entirely different argument from experience is pulling on them. That argument is the final argument I will discuss.

\section{The Argument from the Presented Experience, I}

If the moving spotlight theorist admits that presentness makes no difference to how things look, and makes no difference to how experiences feel, what possible connection could there be between experience and passage? Without either of these two claims, how is an argument from experience supposed to even get started?

Let's go back to the beginning. Suppose (modifying my earlier example) that yesterday (Monday) I meditated (with my eyes open) in my green room and that today (Tuesday) I am meditating in my red room. The B-theory says that I see green on Monday and I see red on Tuesday, and that is all (all that is relevant in this context anyway). So the picture of reality that goes with the B-theory is the one in figure 5 .

The moving spotlight theory says that this picture is incomplete. For one thing, it has left out which time has presentness. So the picture should look like the picture in figure 6. Again, the yellow halo indicates which things have presentness. (And again, the moving spotlight theory says that the picture is still incomplete. It was the case that Monday has presentness, but this fact is not evident in the picture. But that will not matter for now.)

Something about our experience is supposed to favor the second picture over the first. What about our experience? And how does that feature of our experience favor the second picture?

The third argument I want to discuss contains answers to these questions. ${ }^{21}$ The argument comes in two stages. Stage 1 of the argument aims to establish that

${ }^{21}$ As I said, I think that many arguments for the moving spotlight theory that appeal to experience are attempts to articulate this argument. But the only explicit presentation of something like this argument that I know of is in (Balashov 2005). 
Figure 5: My meditations according to the B-theory

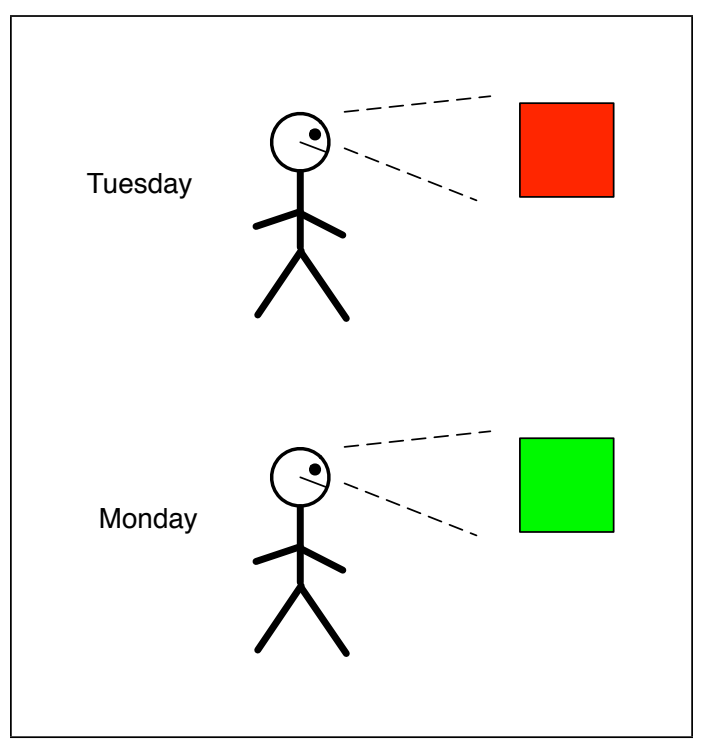

Figure 6: My meditations according to the moving spotlight theory

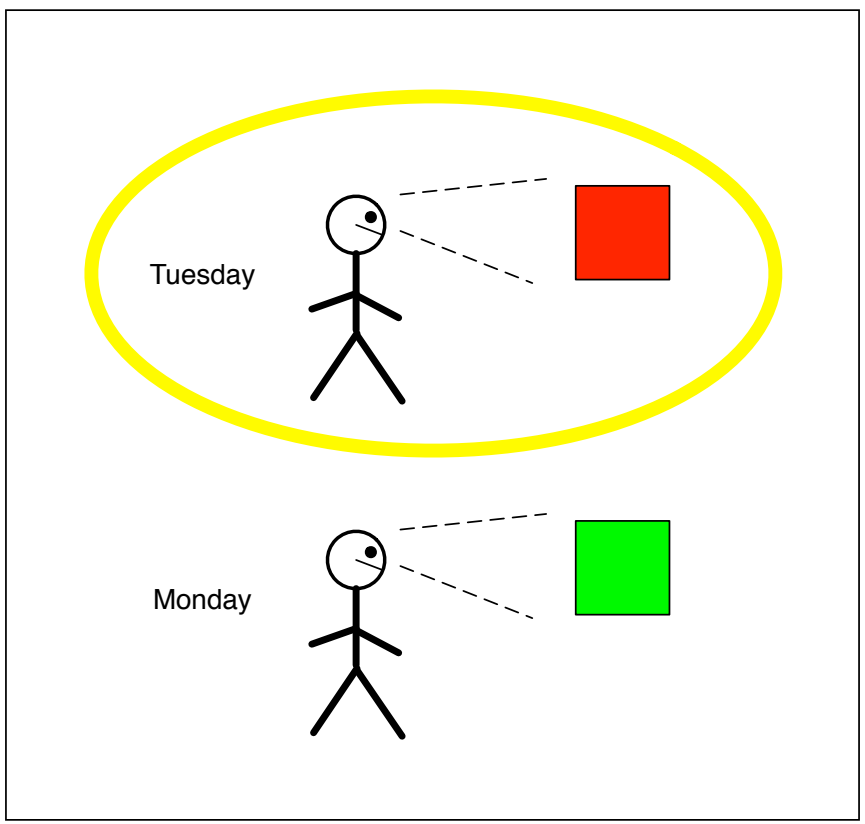


some time has presentness. The following speech is an attempt to articulate stage 1 (I present it in the first person):

Stage 1. The B-theory does not make very good sense of my experience. Yes, I see red on Tuesday and I see green on Monday. According to the B-theory that is all. Nothing distinguishes the red experiences from the green experiences (other than the colors they are experiences of). This is hard to believe. Although I see green on Monday it is only the red experiences (the experiences of red things) that are available to me or presented to me. So the red experiences are distinguished. But the fact that only the red experiences are presented to me is missing from the B-theory.

The moving spotlight theory makes better sense of my experience. It makes better sense of my experience for two connected reasons. First, it does not say that nothing (other than color) distinguishes the red from the green experiences. Instead, it says that the spotlight of intrinsic privilege shines on the red experiences but not the green ones. And second, the experiences that theory says are intrinsically privileged are the only ones that are available to me or presented to me.

That is stage 1. Stage 2 aims to establish that which time has presentness changes. An attempt to articulate stage 2 goes like this:

Stage 2. Which experiences are presented to me has been changing. Not only are the red experiences available to me, but (as I remember) the green experiences were available to me. Now suppose that stage one of the argument has been successful. The experiences available to me are the ones that have presentness. Then it follows that while Tuesday and things that happen on Tuesday have presentness, Monday and things that happened on Monday must have had presentness. But then which time has presentness has changed. Time has passed. And this change in which time has presentness cannot be understood to mean: on Monday, Monday has presentness while on Tuesday, Tuesday has presentness. For then the facts about presentness do not distinguish my 
Monday experiences from my Tuesday experiences. One day's experiences are distinguished only if one and only one time has presentness simpliciter.

That is the argument from the presented experience. It is certainly an argument from experience. And it is certainly distinct from the other two arguments I have discussed. Nowhere does the argument say that things look present, or that the passage of time is represented by some experience. And nowhere does the argument say that presentness makes a difference to how experiences feel. It does not say that experiences with presentness have some special phenomenal character. The argument does have this much in common with the argument fron phenomenology: it says that experiences with presentness are special. But instead of saying that they feel different this argument says that experiences with presentness are the only ones that are available to me.

It will help to have a more explicit statement of the premises of the argument. I want to focus just on stage 1 . The moving spotlight theorist and the B-theorist agree that I have both green and red experiences (at different times). The moving spotlight theorist insists

(P1) Only the red experiences are available to me.

But, the moving spotlight theorist says, according to the B-theory "nothing distinguishes the red experiences from the green experiences (other than the colors they are experiences of)." This is meant to support

(P2) If the B-theory is true then either both the red and green experiences are available to me, or neither the red nor the green experiences are available to me.

From this it follows

(C) The B-theory is false.

The same kind of argument does not work against the moving spotlight theory because the analogue of (P2) is false in the moving spotlight theory. The moving spotlight theory can say that all and only the experiences with presentness are available to me. And only the red experiences have presentness. 
What is wrong with this argument? The argument makes use of a new and unexplained notion: the notion of an experience being available to someone. One reply to the argument focuses on this notion. What is it for an experience to be available to someone? A natural answer is that at any time the experiences that are available to someone at that time are the experiences he has at that time. This answer makes availability a time-relative (and, of course, person-relative) notion. How does the argument look if we read it as using this notion of availability? Since (P1) is uttered on Tuesday, a reading on which it is true makes it equivalent to

(P1.1) Only the red experiences are available to me on Tuesday.

But then I reject the analogous reading of $(\mathrm{P} 2)$ :

(P2.1) If the B-theory is true then either both the red and green experiences are available to me on Tuesday, or neither the red nor the green experiences are available to me on Tuesday.

That's not right. The green experiences certainly are not available to me on Tuesday. The moving spotlight theorist supported (P2) by saying that there are no relevant differences between the experiences. But he was looking in the wrong place. The difference in availability is grounded in a difference in the relation each experience bears to the temporal perspective from which I ask which experiences are available to me.

Moving spotlight theorists will insist that this is not how they intended the argument to be understood. The notion of availability the argument employs, they will say, is one that is not time-relative ${ }^{22}$ So the intended reading of (P1) is

(P1.2) Only the red experiences are available to me simpliciter.

(The "simpliciter" is meant to indicate a lack of time-relativity.) Similarly, the intended reading of the second premise is

\footnotetext{
${ }^{22}$ Understood this way this argument for passage resembles Lewis's argument from temporary intrinsics for the doctrine of temporal parts (Lewis 1986, 202-04). The resemblance will become closer in the next section.
} 
(P2.2) If the B-theory is true then either both the red and green experiences are available to me simpliciter, or neither the red nor the green experiences are available to me simpliciter.

In response to this I want to put my foot down and say that it makes no sense to talk about which experiences are available to me simpliciter. The argument fails because both premises (P1.2) and (P2.2) falsely presuppose that this does make sense. If I am tempted to say that the red experiences are available to me simpliciter it is only because the red experiences occur on Tuesday and it is on Tuesday that I sit around contemplating which experiences are available to me. So they are the ones that are available to me at the time I do the contemplating.

\section{The Argument from the Presented Experience, II}

Sometimes I think that this is a perfectly adequate response to the argument from the presented experience. But at other times I think the response is weak. In this section I want to present the reasons I have for thinking it is weak. Then I will suggest a different response to the argument that is compatible with those thoughts.

When I think about the spatial analogue of this debate it is not so obvious to me that the B-theorist is right. So what is the spatial analogue of the debate? I have been talking about a story in which I see different colors on different days. I see only red on Tuesday and only green on Monday. The spatially analogous story is one in which I simultaneously see different colors in different places. So in the story I will be simultaneously located in two different places.

Of course, I am already simultaneously located in two different places. I am over here, where my left hand is, and I am also over there, where my right hand is. But anyone who looked in either of the locations I just indicated would see only a hand. In the scenario I have in mind something far more spectacular is going on. In that scenario I am meditating in a red room in Massachusetts while simultaneously meditating in a green room in Florida. Anyone who walked into the red room would say he saw a whole person: head, torso, arms, legs, and so on. Anyone who walked into the green room would say the same.

(Do I manage to be both in Massachusetts and in Florida by having one 
man-shaped part wholly in Massachusetts and another man-shaped part wholly in Florida? Or do I have just one man-shaped part that is simultaneously wholly located in Massachusetts and in Florida? These questions are analogues of questions about how I persist over time: do I exist on Monday and on Tuesday by having a temporal part that exists only during Monday and another that exists only during Tuesday? Or am I wholly located during both days? The temporal versions of these questions will be important soon. For now set them aside.)

The "spatial B-theory" says that I see red in Massachusetts and I see green in Florida and that is all. The picture of reality that goes with this theory is the one in figure 7 .

Figure 7: My meditations according to the spatial B-theory

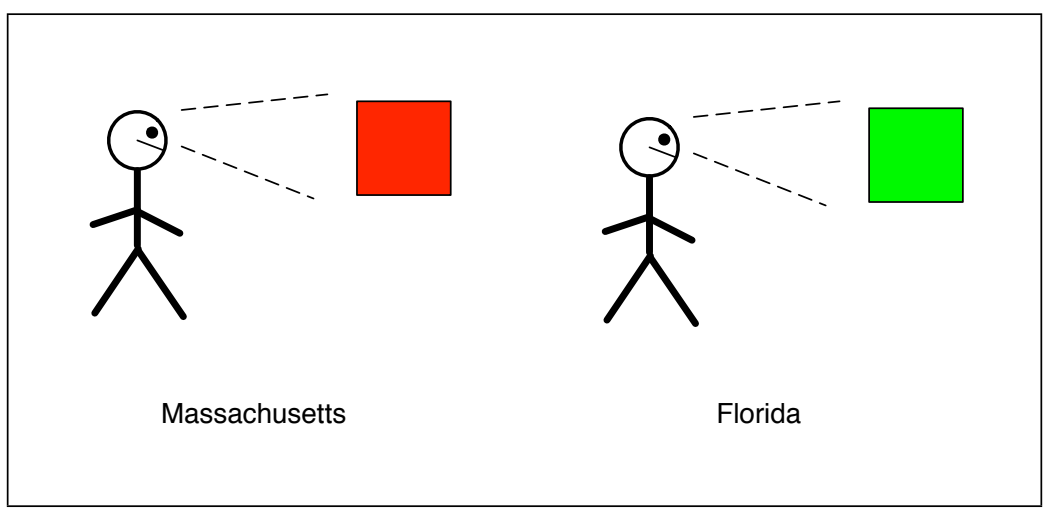

What picture goes with the "spatial moving spotlight theory"? That picture is obtained from the picture in figure 7 by adding an special intrinsic property had by only the things in Massachusetts (see figure 8). A yellow halo represents this property.

The spatial moving spotlight theory does not just endorse the picture in figure 8. It also says that there is some spatial analogue of "primitive tense." So the theory also says something like this: although the spotlight shines on Massachusetts, to the south it shines on Florida. This is a very mysterious statement. Fortunately, I think we can set aside this part of the theory. Let us just focus on the part that says that the spotlight shines on Massachusetts. 
Figure 8: My meditations according to the spatial moving spotlight theory

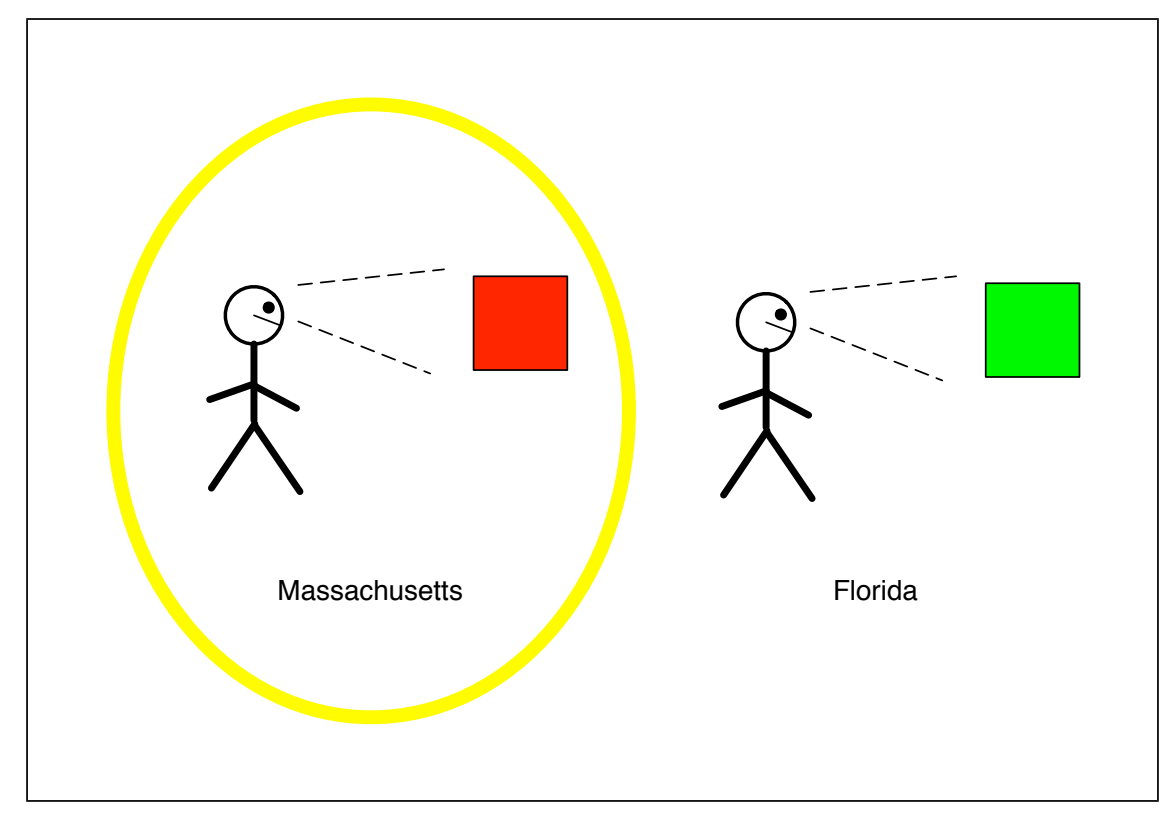

Now: which of the spatial pictures is better - the one in figure 7 or the one in figure 8? It is hard to say, because both are ridiculous. Both say that I am simultaneously in Massachusetts and in Florida. But I am not; I am only in Massachusetts.

Still, suppose that I have become convinced that I am simultaneously in Massachusetts and in Florida. Perhaps the oracle of philosophy revealed it to me. And suppose you have become convinced of something similar, and are contemplating a similar pair of pictures depicting you. So we accept the common presupposition of the spatial B-theory and the spatial moving spotlight theory. Now which theory is better?

Again the debate will focus on a question about which experiences are available to me. The spatial moving spotlight theorist will say: you see red in Massachusetts and green in Florida. But there must be more to it than that. Surely you think that it is only the red experiences that are available to you. The spatial spotlight theory captures this fact and the spatial B-theory does not.

The response to this argument that parallels the one I described in the last 
section is: it makes no sense to talk about which experiences are available to you simpliciter. The only intelligible notion of availability (that is relevant in this context) is location-relative. The red experiences are available to you in Massachusetts and the green ones are available to you in Florida. Insofar as you are tempted to say that the red ones are available to you simpliciter, that is just because this entire conversation is going on in Massachusetts.

Sometimes I just find this response difficult to believe. Maybe the following is one way to bring out the difficulty. Try turning the argument around. Suppose that the oracle, instead of telling you that you are in Massachusetts and in Florida, told you instead (what you already believed) that the special intrinsic property that the spatial moving spotlight theorist believes in does not exist. If someone less reliable than the oracle then told you that you are in Florida as well as in Massachusetts, I bet you would be tempted to reply with the following argument:

That is not true. I am seeing red. The guy in Florida is not seeing red.

By Leibniz's Law, we are distinct.

Plenty of people, myself included, do want to give this argument. Plenty want to give this argument even in a context in which the debate about the passage of time has not been mentioned. For example, some versions of the many worlds interpretation of quantum mechanics say something like what the oracle said. They say that each of us is simultaneously located in widely separated regions of space (or in regions of space that are not even spatially connected to each other), having quite different experiences in the different regions. When I have tried to explain this theory to students many of them insistently object and give an argument like the argument from Leibniz's law.

But the argument from Leibniz's Law is good only if there is an intelligible notion of availability that is not location-relative. If there is no such notion then the argument is unsound. (Exactly why it fails depends on how it is interpreted. One of the premises is: "BAS is seeing red." If this means "BAS is seeing red simpliciter" (where here the "simpliciter" indicates an absence of location-relativity) then it contains a nonsensical notion and so is not true. If it means "BAS is seeing red in Massachusetts" then it is true. But then the argument is valid only if the 
next premise is interpreted to mean "The guy in Florida is not seeing red in Massachusetts." And we have been given no reason to accept this premise. We only know about what the guy in Florida is seeing in Florida.)

So I am sometimes tempted to think that there is an intelligible notion of availability that applies to me and is not location-relative. Now this does not entail that there is also an intelligible notion of availability that applies to me and is not time-relative. But I think that time and space are similar enough that I would not want to defend a view that accepted one kind of relativity and not the other. And once I accept a time-independent notion of availability I cannot give the objection to the argument from the presented experience that I described in the last section.

Fortunately there is another reply to that argument that is compatible with the claim that there is a notion of availability that is not time-relative. In the rest of this section I want to explain how that reply works.

Look back at figure 5. I said that it contains the picture of reality that goes with the B-theory. But I presupposed some metaphysical claims in addition to the B-theory when I drew that picture. In particular, I presupposed that I exist on both Monday and Tuesday. This assumption certainly does not follow from the B-theory. It is an independent assumption.

Of course, even though this assumption is independent of the B-theory it looks like it is true in the scenario that figure 5 depicts. That scenario is one in which today I am meditating in my red room and in which yesterday I meditated in my green room. (Today is Tuesday, yesterday is Monday.) Certainly if I meditated in my green room yesterday then I existed yesterday.

But wait: not every theory of persistence through time endorses this last claim. The stage view, in particular, does not ${ }^{23}$ The stage view says that "BAS meditated in his green room on Monday" is true on Tuesday but denies that I exist on Monday. The stage view is important because if I accept the stage view then I can accept a notion of availability that is not time-relative but still reject one of the moving spotlight theorist's premises.

Before saying how that goes let me explain the stage view in more detail. The

${ }^{23}$ See (Sider 1996) for an explanation and defense of the stage view. The idea of appealing to the stage theory to defend the B-theory comes from Balashov (2005). 
stage view says that I exist at only one time. Instead of identifying me with a fourdimensional spacetime worm, it identifies me with just a single three-dimensional "slice" of that worm. But the theory does not go on to say (for example) that "BAS was a child" is false. (It had better not.) Why not? Well, that BAS was never a child follows from the claim that BAS exists at only one time only if a certain analysis of temporal predication is correct. That analysis is, roughly:

- " $S$ was F" is true at $t$ iff $S$ exists at some time $T$ earlier than $t$ and at $T S$ is F.

But the stage view rejects this analysis. It uses an alternative analysis: temporal counterpart theory. That analysis of temporal predication says, roughly (here $S$ is an expression that refers to a person):

- " $S$ was F" is true at $t$ iff at a time earlier than $t$ there is a person (who exists for just an instant) who (i) is $S$ 's temporal counterpart, and (ii) is F.

Who are my temporal counterparts? We do not need a definitive answer here. Different views about the "persistence conditions" for human persons correspond to different candidate counterpart relations. One common theory says that my counterparts are the people who are physically and psychologically continuous with me in the right way. This package of views - the claim that no person exists at more than one time and temporal counterpart theory - is the stage view.

To summarize, the stage view says this about me: there is no time at which I am a child. But I was a child. That is because there is someone who is a child and who exists at a time earlier than the current time and who is psychologically continuous with me.

Now let us look at what the argument from the presented experience looks like if I accept the stage view.

If I accept the stage view then I reject both the picture in figure 5 and the picture in figure 6. Instead the pictures we need to focus on are the picture in figure 9 and the picture in figure 10. (In these pictures the stick figure drawn solid is me. The one drawn dashed is someone else.)

The first is the picture the B-theorist draws and the second is the picture the moving spotlight theorist draws. Importantly, the two episodes of seeing in figure 9 
Figure 9: My meditations according to the B-theory (on the stage view)

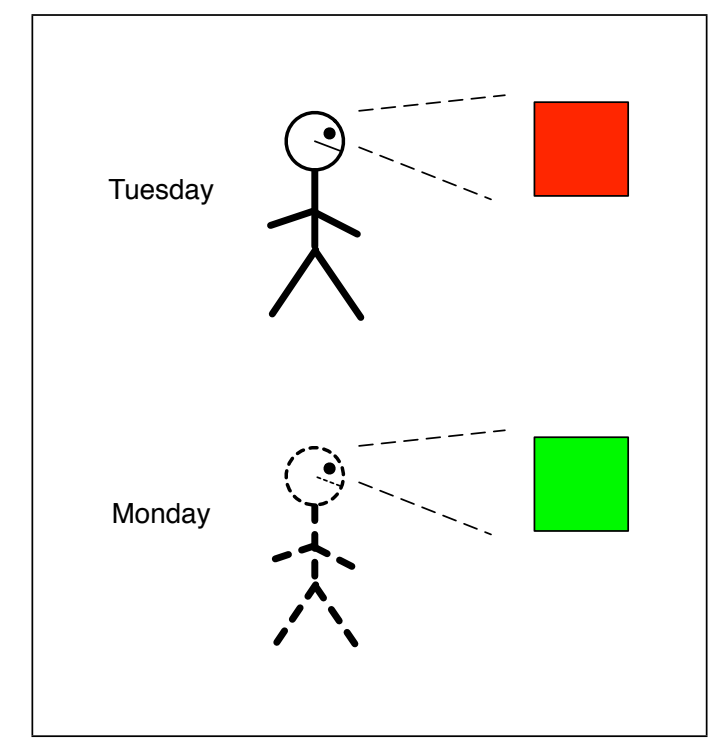

are not exactly the same except for the color seen. There is an extremely important difference: in that picture I see red and someone else sees green 24

Once I accept the stage view I can say that it makes sense to ask which experiences are available to me simpliciter. My answer is: all the experiences someone (tenselessly) has are available to that person. So I say that (P1.2) makes sense and is true. But the argument from the presented experience still fails, because now (P2.2) is false.

\section{The Argument from the Presented Experience, III}

I have now presented two responses to the argument from the presented experience. The second response sheds additional light on the first one. So I want to go back and say a bit more about it.

\footnotetext{
${ }^{24}$ Of course, "I saw green on Monday" is true because that person sees green on Monday. The stage view also says that while the guy who exists on Monday is (this is the tenseless "is") distinct from me, he was identical to me. Neither of these facts is important right now though.
} 
Figure 10: My meditations according to the moving spotlight theory (on the stage view)

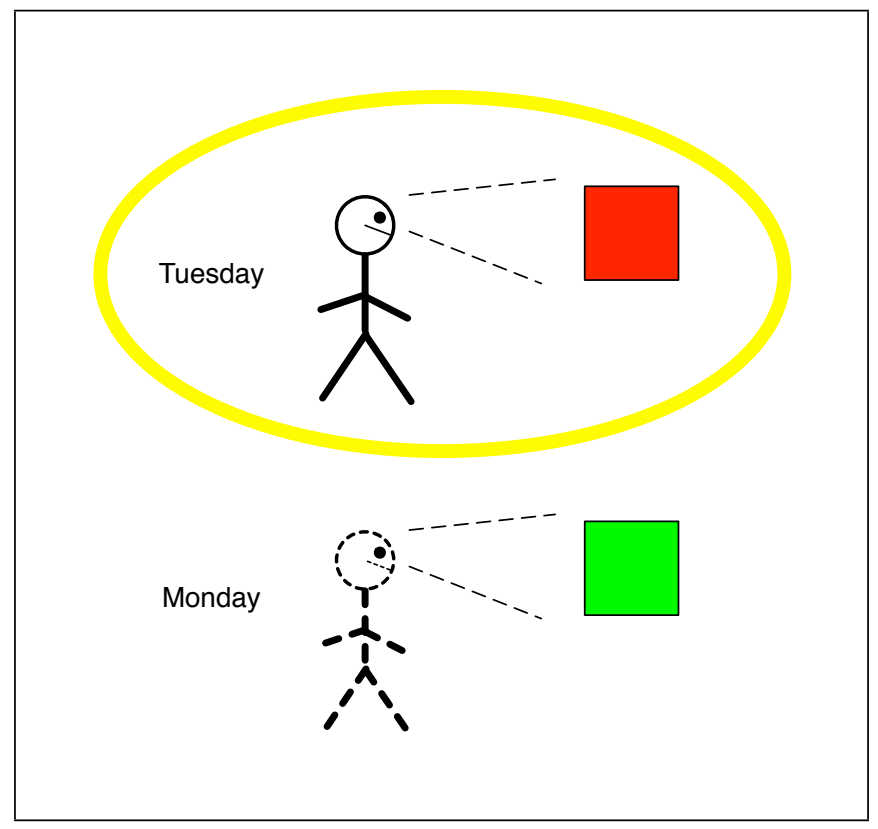

The first response is available to a B-theorist who rejects the stage view. But there are two alternatives to the stage view: endurantism, the thesis that a persisting thing is wholly located at each time at which it exists; and perdurantism, the thesis that a persisting thing has an instantaneous temporal part at each time at which it exists. A B-theorist who accepts either of these theories should deny that it makes sense to ask which experiences are available to me simpliciter.

But endurantism and perdurantism are not in exactly the same position with respect to the argument. Perdurantism provides a kind of half-way house between the two replies to the argument. Accepting it allows one to accept some of the motivations behind the second reply without going so far as believing the stage view ${ }^{25}$ Let me explain.

A B-theorist who accepts perdurantism can accept that there are some things

${ }^{25}$ Ted Sider pressed me on this point. I owe a lot of what I say in this section to correspondence with him. 
to which experiences are available simpliciter: instantaneous stages of persons. All and only the experiences a stage ever has are available to it. But since the theory identifies persons (like me) with four-dimensional spacetime worms rather than stages, no experiences are available simpliciter to me, or to persons generally. So a B-theorist who accepts perdurantism can still reject (P1.2) and (P2.2) of the argument.

But he does not need to say that the ideas behind the second reply are completely off-track. He can say something like this:

The discussion of your meditations in Massachusetts and Florida definitely motivates the idea that there is a space- and time-independent notion of availability. Since endurantism cannot recognize such a notion endurantism is false. But the discussion does not go so far as to motivate the idea that this notion applies to you. The claim that some experience is available simpliciter to you is overreaching. Reflection on your experience can only justify being confident that the red experiences are available simpliciter to something. And perdurantism is consistent with that: it says that the red experiences are available simpliciter to your Massachusetts and your Tuesday stages (the stages that are "doing the thinking" at the place, or time, at which you reflect in the scenarios) 26

Notice that the perdurantist can have only modest ambitions for the argument from Leibniz's Law. He cannot endorse it as formulated above. He cannot use it to refute the claim that I have multiple spatial locations. Instead he can endorse a modified version of the argument that refutes the claim that I am wholly located in more than one location. But maybe that is a good thing; maybe it should not be so easy to

${ }^{26}$ This claim resembles something Lewis says about the problem of temporary intrinsics. It seemed at first that Lewis's complaint about endurantism was that if endurantism is true then no tennis ball (for example) is round simpliciter. But that is also false on perdurantism, his preferred theory. Lewis (1988) corrected this impression: his complaint about endurantism is that if endurantism is true then nothing is round simpliciter. It is enough if some things - stages of tennis balls are round simpliciter, even if no tennis ball is. 
refute the many worlds interpretation of quantum mechanics.

So what are the relative merits of the perdurantist and the stage-theoretic responses to the argument from the presented experience? How one answers this question turns on how one thinks the motivation for accepting a time-independent notion of availability works. The perdurantist (who is also a B-theorist) says: "I am confident that the red experiences are available simpliciter to something, but I am not so sure whether they are available simpliciter to me. Maybe they are just available to a part of me - my current stage." One might find this claim difficult to believe. I myself am inclined to believe that I can only be confident that the red experiences are available simpliciter to something by being confident that they are available simplicter to me. A B-theorist who thinks this should prefer the stage view to perdurantism.

\section{Conclusion}

"An excellent reason to believe in an objective passage of time is that our experience suggests that there is such a thing." In this paper I have tried to figure out what argument lies behind claims like this. I have discussed three arguments in detail. The first argument starts from the claim that it is part of the content of our experience that there is an objective passage of time. The second starts from the claim that our experiences have some distinctive phenomenal character that is best explained by the hypothesis that there is an objective passage of time. I do not think these arguments are very good.

The third argument is better. It starts from the idea that not all of the experiences I (tenselessly) have are on a par. Some of them are special. Some of them are "presented to me" while the others are not. What's more, which ones are presented keeps changing. The moving spotlight theorist says that his theory can make better sense of this phenomenon. I suggested three responses a B-theorist can make to this claim. He can reject talk of which experiences are presented to someone, or available to someone, simpliciter. Or he can accept such talk, agree that some experiences are available to him simpliciter, but deny that only some of his experiences are available to him simpliciter. He can embrace the stage view and say instead that 
all his experiences are available to him simpliciter. Finally, he can accept talk of time-independent availability but deny that some of his experiences are available to him simpliciter. He can embrace perdurantism and say instead that the experiences are available simpliciter only to his stages, not to him ${ }^{27}$

\section{References}

Balashov, Yuri (2005). "Times of Our Lives: Negotiating the Presence of Experience." American Philosophical Quarterly 42: 295-309.

Byrne, Alex (2009a). "Experience and Content." Philosophical Quarterly 59: 42951.

- (2009b). "Sensory Qualities, Sensible Qualities, Sensational Qualities." In Brian P. McLaughlin and Ansgar Beckermann (eds.), The Oxford Handbook of Philosopy of Mind, chapter 14. Oxford: Oxford University Press.

— (forthcoming). "Knowing What I See.” In D. Smithies and D. Stoljar (eds.), Introspection and Consciousness. Oxford: Oxford University Press.

Callender, Craig (2008). "The Common Now." Philosophical Issues 18: 339-61.

Dainton, Barry (2011). “Time, Passage, and Immediate Experience.” In Craig Callender (ed.), The Oxford Handbook of Philosophy of Time, chapter 12. Oxford: Oxford University Press.

Evans, Gareth (1982). The Varieties of Reference. Oxford: Oxford University Press.

Forrest, Peter (2004). "The real but dead past: a reply to Braddon-Mitchell." Analysis 64: 358-62.

Grünbaum, Adolf (1967). "The Status of Temporal Becoming." Annals of the New York Academy of Sciences 138: 374-95.

Hare, Caspar (2010). "Realism About Tense and Perspective." Philosophical Compass 5: 760-769.

Hestevold, H. Scott (1990). "Passage and the Presence of Experience." Philosophy and Phenomenological Research 50: 537-52.

Le Poidevin, Robin (2007). The Images of Time. Oxford: Oxford University Press.

${ }^{27}$ Many thanks to Fred Feldman, David Gray, Caspar Hare, Liz Harman, Mary Lou Maher, Ned Markosian, L. A. Paul, Agustin Rayo, Ted Sider, and Steve Yablo. This paper would have been far worse without their feedback and advice. 
Lewis, David (1986). On the Plurality of Worlds. Oxford: Basil Blackwell.

— (1988). "Rearrangement of particles: reply to Lowe." Analysis 48: 65-72.

Maudlin, Tim (2007). "On the Passing of Time." In The Metaphysics Within Physics, chapter 4. New York: Oxford University Press.

McTaggart, J. E. M. (1908). “The Unreality of Time.” Mind 17: 457-74.

Mellor, D. H. (1981). Real Time. Cambridge: Cambridge University Press.

Paul, L. A. (2010) “Temporal Experience.” The Journal of Philosohpy 107: 333-59.

Price, Huw (1996). Time's Arrow and Archimedes' Point. New York: Oxford University Press.

Prior, A. N. (1959). “Thank Goodness That's Over.” Philosophy 34: 12-17.

Prosser, Simon (2007). "Could We Experience The Passage of Time?" Ratio 20: 75-90. — (forthcoming-a). "Passage and Perception." Nous.

- (forthcoming-b). "Why Does Time Seem To Pass?" Philosophy and Phenomenological Research.

Schlesinger, George (1994). "The Stream of Time.” In L. Nathan Oaklander and Quentin Smith (eds.), The New Theory of Time, 257-85. New Haven: Yale University Press.

Sider, Theodore (1996). “All The World's A Stage.” The Australasian Journal of Philosophy 74: 433-53.

Siegel, Susanna (2011). The Contents of Visual Experience. Oxford: Oxford University Press.

Skow, Bradford (forthcoming). "On the Meaning of the Question 'How Fast Does Time Pass?'." Philosophical Studies.

Smart, J. J. C. (1980). “Time and Becoming.” In Peter van Inwagen (ed.), Time and Cause: essays presented to Richard Taylor, pp.3-15. Dordrecht, the Netherlands: D. Reidel Publishing Company.

Smith, Quentin (1994). “The Phenomenology of A-Time.” In L. Nathan Oaklander and Quentin Smith (eds.), The New Theory of Time, pp.351-59. New Haven: Yale University Press.

Taylor, Richard (1992). Metaphysics. 4th edition. Englewood Cliffs, NJ: Prentice Hall.

Zimmerman, Dean (2005). "The A-theory of Time, the B-theory of time, and 'Tak- 
ing Tense Seriously',” Dialectica 59: 401-57. 